\title{
Assessment of the Black Sea Temperature and Salinity Climatic Fields for the Recent Climatological Period (1991-2020)
}

\author{
N. V. Markova ${ }^{\bowtie}$, V. N. Belokopytov, O. A. Dymova, \\ N. A. Miklashevskaya
}

Marine Hydrophysical Institute of RAS, Sevastopol, Russian Federation

$凶$ n.v.markova@mail.ru

Purpose. The study is aimed at assessing a new climatic array of the Black Sea temperature and salinity calculated using hydrological observations for the standard 30-year climatological period 1991-2020 (according to the World Meteorological Organization definition).

Methods and Results. New array of the temperature and salinity climatic fields was assessed by the results of numerical experiments. In the experiment, annual variation of the Black Sea hydrophysical parameters was reconstructed by the numerical model. Modeling included the scheme of assimilating the data of the climatic temperature and salinity array assessed. In contrast to the averaged data of the field observations, the modeled fields are compliant with equations of motion. Besides the temperature and salinity three-dimensional fields, the three-dimensional climatic fields of the Black Sea currents were also reconstructed for each day of a climatic year that is impossible using the observational data only. Spatial-temporal variability of the modeled threedimensional fields was analyzed. The integral characteristics of the Black Sea water dynamics for the recent 30-year climatic period were studied and compared with the analogous ones for the previous century. Simulation was carried out by three-dimensional non-linear model of the Black Sea dynamics developed in Marine Hydrophysical Institute. The horizontal resolution of the model was $5 \mathrm{~km}$, and the EMODNet bathymetry was used. The performed calculations showed that the increased spatial resolution of the temperature and salinity climatic array for the recent period made it possible to reconstruct the dynamics of the Black Sea in all layers in more detail. At the same time, significant small-scale variability of salinity fields was revealed. It was most pronounced at the deep-water horizons.

Conclusions. Modeling using a new array of thermohaline fields revealed an increase in the integral temperature of the upper mixed layer in comparison with the experiment with assimilation of the previous version of the climatic array. At that, thinning and «break» of the cold intermediate layer found in the central part of the sea, indicates warming of the sea upper layer during the last 30 years. The highest noise detected at the deep-water horizons in the modeled salinity fields is related to quantity and quality of the salinity data resulted from the field observations. Taking into account insufficient calibration facilities for measuring seawater electrical conductivity, the next version of climatic TS-array requires a more strict procedure for verifying and processing the observation data obtained in the deepsea layers.

Keywords: climatic fields, modeling, assimilation, Black Sea, temperature, salinity, currents

Acknowledgments: numerical experiments on modeling of the Black Sea dynamics were carried out within the framework of the state task on theme No. 0555-2021-0003. The experiment results were processed and analyzed within the framework of the state task on theme No. 0555-2021-0004.

For citation: Markova, N.V., Belokopytov, V.N., Dymova, O.A. and Miklashevskaya, N.A., 2021. Assessment of the Black Sea Temperature and Salinity Climatic Fields for the Recent Climatological Period (1991-2020). Physical Oceanography, [e-journal] 28(4), pp. 392-403. doi:10.22449/1573160X-2021-4-392-403

DOI: 10.22449/1573-160X-2021-4-392-403

(C) N. V. Markova, V. N. Belokopytov, O. A. Dymova, N. A. Miklashevskaya, 2021

(C) Physical Oceanography, 2021 


\section{Introduction}

The technique of reconstructing the Black Sea climatic fields on the basis of assimilation in the numerical model of mean annual data of field observations has already been developed. Using the numerical model of Marine Hydrophysical Institute (hereinafter referred to as the MHI model) [1] with the assimilation of field observations, the climatic fields of temperature, salinity, current velocities, and level of the Black Sea were calculated on a $15 \mathrm{~km}$ grid horizontally [2-6], and then on a $5 \mathrm{~km}$ in [7]. The frequency of observational data assimilation in calculations the climatic fields by MHI model was studied in detail in [8].

A change of the data array assimilated can entail significant changes in the hydrophysical fields reproduced by the numerical model [4, 5]. As a rule, this effect is associated with an increase in the amount of hydrological observation data that formed the assimilated array (hereinafter referred to as the HC-array ("hydrological climate”)). At the period under consideration (1991-2020), the technical level of measuring instruments has significantly increased, as well as the accuracy of the data obtained. At the same time, the organization of observations in the open sea has changed. The number of shipborne oceanographic surveys, carried out according to pre-planned schemes of expeditionary operations, has decreased. Autonomous profiling floats, the trajectories of which are completely determined by the instant field of currents, become the main measuring platforms. This entails changes in the spatial distribution of the data, in the ratio of instrumental and systematic errors, as well as in other factors affecting the results of climatic calculations.

An assessment of the HC-array quality can be carried out by analyzing the results of modeling performed with the assimilation of the climatic data forming the array. For this purpose, it is necessary to study the integral characteristics of the seawater dynamics and the spatial-temporal variability of the Black Sea three-dimensional hydrophysical fields, reconstructed by a numerical model. This method makes it possible to reveal the features of the threedimensional climatic fields of temperature and salinity of the Black Sea, constructed from hydrological observations for the new 30-year climatic period of 1991-2020 (hereinafter - HC30). The analysis of hydrophysical fields' features is carried out using the comparison with the Black Sea climatic fields calculated with the assimilation of HC-array previous version. This old version was constructed on the basis of hydrological data for around 100-year period of 1910-2003 (hereinafter - HC100). Based on the results of numerical experiments, the impact of changes in the assimilated array of temperature and salinity on the reconstructed the Black Sea climatic circulation is determined.

\section{Calculation methodology and the data used}

Numerical experiments were carried out on the basis of the MHI model [1] according to the scheme presented in [7]. The MHI model is based on the complete equations of ocean thermohydrodynamics using the Boussinesq and hydrostatic approximations. The sea surface height is calculated assuming that the linearized kinematic condition is met. The density nonlinearly depends on temperature and salinity; the equation of state is given in [9]. At the bottom, the conditions of impermeability and absence of heat and salt fluxes are set, friction on the bottom is 
not taken into account. On the solid lateral boundary, the free slip and impermeability conditions are satisfied, and the normal derivatives are set equal to zero for the temperature and salinity. At river mouths and straits, Dirichlet conditions are set for temperature, salinity and velocity. The tangential wind stress [6], heat fluxes [10], precipitation and evaporation [11] are specified on the free surface.

Unlike research [7], a more accurate bathymetry EMODNet (URL: https://www.emodnet-bathymetry.eu) was applied in the calculations. Vertical turbulent mixing was described using the Pacanowski - Philander parametrization [12]. Horizontal turbulent viscosity and diffusion are represented by biharmonic operators with constant coefficients equal to $10^{17} \mathrm{~cm}^{4} / \mathrm{s}$. The finite-difference approximation of the MHI model equations is implemented on the $C$ grid according to Arakawa terminology [13]. The horizontal spatial resolution was $5 \mathrm{~km}$, which corresponds to $(1 / 16)^{\circ}$ in longitude and $(1 / 23)^{\circ}$ in latitude. Vertically 38 model horizons are specified with a smaller step in the upper layer. The version of the MHI model with $5 \mathrm{~km}$ resolution was validated on the basis of field data during the international scientific project MyOcean [14] and is used in the operational forecasting system of the Black Sea state [15].

According to the scheme tested in [8] and applied in [7], at each $40^{\text {th }}$ time step the temperature and salinity fields from HC-array, interpolated to the grid nodes, were assimilated in the model. The assimilation of HC-fields is realized by including into the right-hand sides of the both heat and salt advection - diffusion equations additional assimilation terms, which depend on the difference between the model and HC-values:

$$
\begin{aligned}
& T_{t}+(u T)_{x}+(v T)_{y}+(w T)_{z}=-k^{H} \nabla^{4} T+\left(k^{T} T_{z}\right)_{z}+\Lambda\left(T^{c l}-T\right), \\
& S_{t}+(u S)_{x}+(v S)_{y}+(w S)_{z}=-k^{H} \nabla^{4} S+\left(k^{S} S_{z}\right)_{z}+\Lambda\left(S^{c l}-S\right),
\end{aligned}
$$

where $T$ is temperature; $S$ is salinity; $u, v, w$ are the velocity components; $k^{H}$ is a horizontal diffusion coefficient; $k^{T}$ is a vertical heat diffusion coefficient; $k^{S}$ is a vertical salt diffusion coefficient; $T^{c l}, S^{c l}$ are the assimilated values of heat and salt from the HC-array. The coefficient structure at assimilation terms is similar to that given in [3]: $\Lambda=\left[1 /\left(\operatorname{Rel}\left(1+\eta^{2}(z)\right)\right] \delta\left(t-t^{a}\right)\right.$, where $\operatorname{Rel}$ is relaxation time; $\eta^{2}(z)$ is a variance of measurement errors normalized to the field variance; $\delta$ is a control parameter ( $\delta=0$ in the relaxation period, $\delta=1$ at the moment of observational data assimilation); $t^{a}$ is a moment of observational data assimilation.

On the basis of the MHI model, two numerical experiments were carried out. The counting time was 18 model years in each of them. The first numerical experiment (denote as E100) was carried out with assimilation of HC100-array calculated from hydrological data for 1910-2003 period ${ }^{1}$. The second experiment (E30) was carried out with the same model settings, but using a new temperature

\footnotetext{
${ }^{1}$ Belokopytov, V.N., 2004. [Thermohaline and Hydrologic-Acoustic Structure of the Black Sea Waters. Ph.D. Thesis]. Sevastopol, 160 p. (in Russian).
} 
and salinity climatic array HC30, built by the methodology of thermohaline field reanalysis [16] for a 30-year period 1991-2020. At the initial moment, in both calculations the velocity components were equated to zero and temperature and salinity fields corresponded to HC. The annual period of circulation was onset approximately 4000 days after the beginning of the model run. In order to evaluate the simulation results, the period from 6252 to 6616 days ( $18^{\text {th }}$ year) of the model run is considered.

Assimilated HC100 and HC30 arrays significantly differ in the averaging period, number of stations, horizontal and vertical spatial distribution, and calculation technique. HC100 is based on 130 thousand hydrological stations averaged on $20 \times 30^{\prime}$ and $40 \times 60^{\prime}$ (depending on data availability) combined grid. HC30 is designed on $10 \times 15^{\prime}$ grid using 25 thousand stations, 6 thousand of which are $A R G O$ profiling floats. A longer averaging period, a larger number of stations, and a lower spatial resolution certainly provide smoother climatic fields in HC100. The main goals of creating $\mathrm{HC} 30$ are to take into account the modern oceanographic conditions in the Black Sea and to clarify the spatial structure of the thermohaline fields, including in the deep layers.

Temperature and salinity HC-fields were linearly interpolated to the model grid nodes, then the fields for each day of the year were reconstructed from the monthly average data. In order to compare with each other, the data of the obtained arrays were averaged over the horizons and the differences (deviations) between them were calculated: for temperature $\Delta T=T^{\mathrm{HC} 100}-T^{\mathrm{HC} 30}$, for salinity $\Delta S$ - similarly.

\section{Analysis of the results}

In Fig. 1 the average annual profiles of temperature and salinity difference between the compared HC-arrays are shown. In the upper 100-m layer, the values of thermohaline parameters from HC30 exceeded the corresponding values from HC100. There is a salinity deviation curve peak at $112.5 \mathrm{~m}$ horizon, where its values in HC100 are higher than in HC30 by $0.02 \%$, which is most likely due to the increase in vertical resolution in HC30. In 250-2000 m layer, the average temperature over the horizons was quite similar (Fig. 1, $a$ ), while for the salinity in 500-1500 m layer the deviations between HC100 and HC30 with different signs were observed (Fig. 1, b). When comparing the monthly average values, it was revealed that the greatest difference between the temperature values reaches $2.32{ }^{\circ} \mathrm{C}$ at $2.5 \mathrm{~m}$ horizon in May (at the maximum heating rate of the upper sea layer), and between the salinity values the maximum difference is $0.24 \%$ at $5 \mathrm{~m}$ horizon in January.

In Fig. 2 the intra-annual variation of temperature and salinity differences (averaged over the horizons) in experiments E100 and E30 is demonstrated. Analysis of temperature deviations revealed that three extremes were observed in the upper 30-m layer: in December - January, in May and in September (Fig. 2, a). 

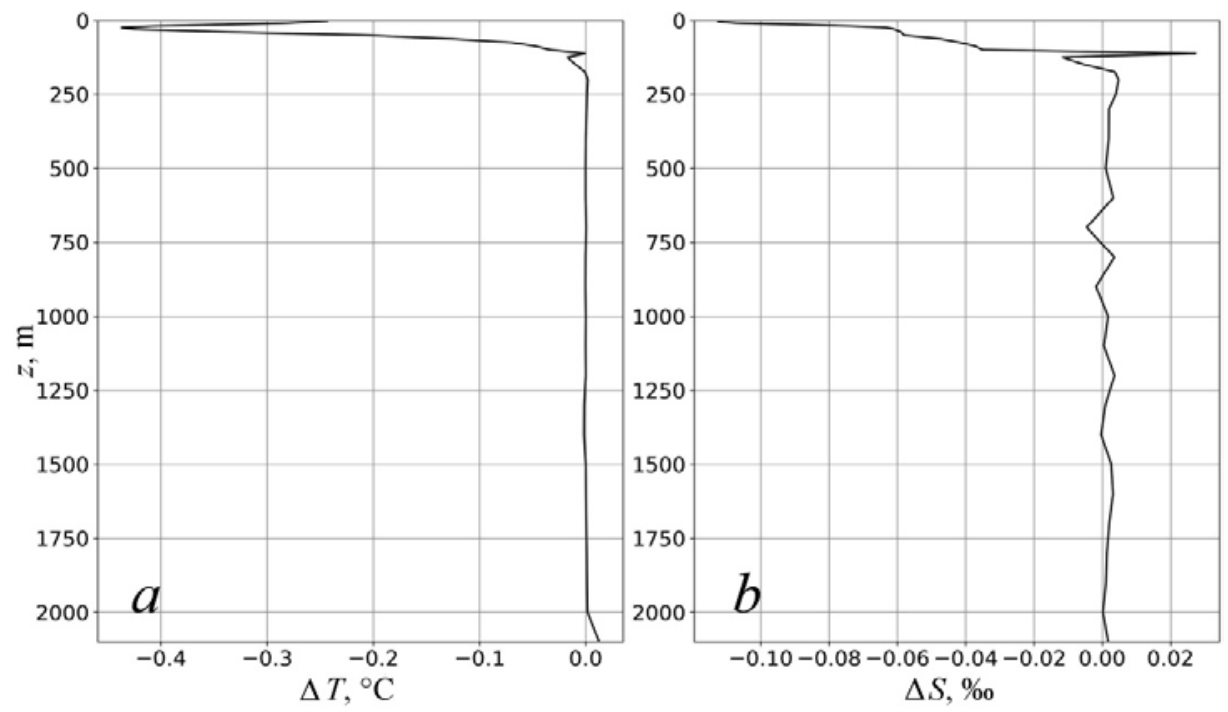

F i g. 1. Change of average annual difference between the HC100 and HC30 data with depth: $a-$ temperature $(\Delta T) ; b-$ salinity $(\Delta S)$

On $50 \mathrm{~m}$ horizon, the extremes were reached in the same periods. However, the quantitative differences between E100 and E30 were less by an order of magnitude relative to those obtained for the upper 30-m layer. At the lower boundary of Cold Intermediate Layer (CIL), in particular over the entire $100 \mathrm{~m}$ horizon, the temperature difference is negative, which means that the temperature in E30 is higher than in E100. The minimum absolute deviation of $0.003^{\circ} \mathrm{C}$ was noted in March, the maximum $0.062{ }^{\circ} \mathrm{C}$ - in February. In 200-300 m layer, the deviations were within $\pm 0.01{ }^{\circ} \mathrm{C}$ (Fig. 2, b). In deep layers (Fig. 2, c), the seasonal curves are qualitatively similar. At horizons of more than $700 \mathrm{~m}$, the absolute difference did not exceed thousandths of a degree, and the extreme values were reached in December - January.

During the year, the difference in salinity values in 2.5-100 m layer is negative, i.e. the average salinity in E30 experiment appeared to be higher. Up to $50 \mathrm{~m}$ depth, the behavior of curves is almost the same (Fig. 2, d), with the greatest absolute deviations in December - January and in June.

At $100 \mathrm{~m}$ horizon, at the end of January and in September, the salinity is higher according to the E30 data, in October - according to E100 data. In 200$300 \mathrm{~m}$ layer, differences in salinity were within $-0.02 \ldots 0.04 \%$ range (Fig. 2, e). At the $700 \mathrm{~m}$ horizon, the salinity in E30 is higher than in E100, with the exception of October. Deeper than the $1500 \mathrm{~m}$ horizon, the salinity in E30 is higher in December - January, and in the rest of the year, the salinity in E30 is lower than in E100 (Fig. 2, f). Thus, the analysis of the modeled fields at different horizons showed that the assimilation of new HC30-array in E30 led to both positive and negative deviations of temperature and salinity from the corresponding values in E100. 

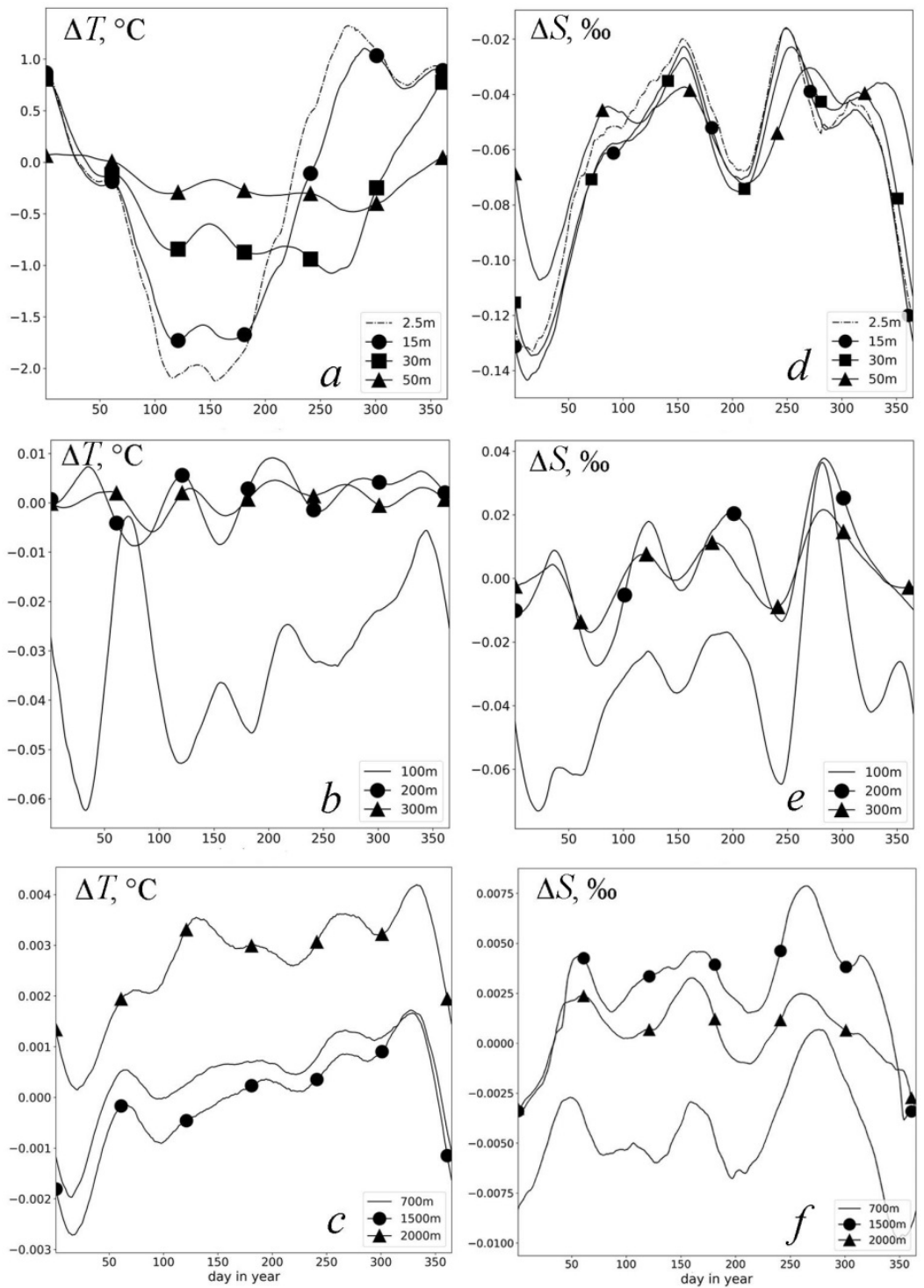

F i g. 2. Seasonal variation of the differences between the E100 and E30 temperature and salinity data: $a, d$ - in the layer 2.5-50 m; $b, e-$ in the layer 50-300 m; $c, f-$ in the layer 700-2000 m

Temporal variability of the kinetic energy density difference, which characterizes the intensity of currents, demonstrates that in E30 the current velocity is higher than in E100 in the entire basin. The maximum absolute deviations were obtained in winter, the minimum - in September at horizons up to $300 \mathrm{~m}$ (Fig. 3, $a$, $b$ ). At the depths of more than $700 \mathrm{~m}$, the maximum difference in the kinetic energy density was reached in February, and the minimum - in November (Fig. 3, c). The differences in the intensity of currents were also confirmed by the analysis of the current maps at different horizons.

Analysis of spatial distribution of hydrophysical characteristics obtained according to the numerical modeling results, revealed the following. 


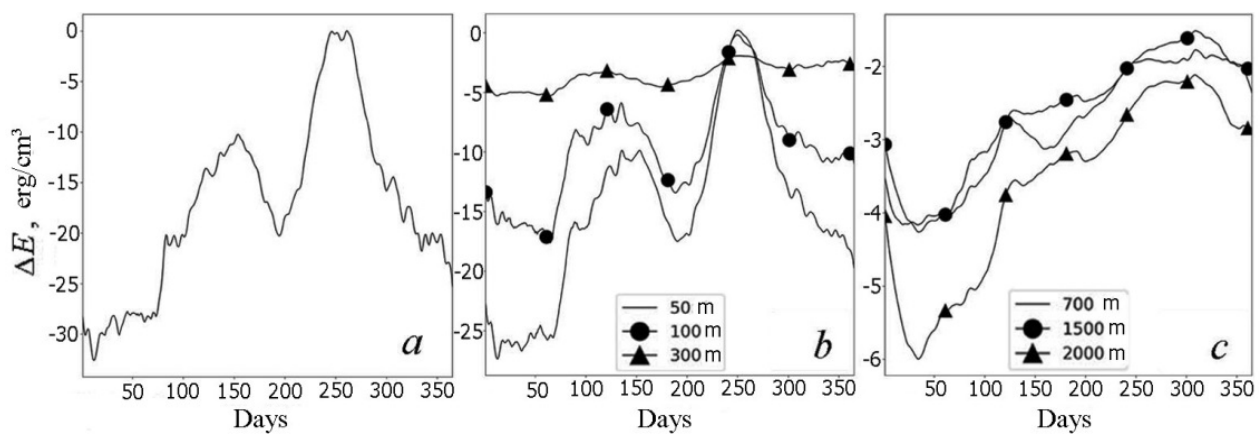

F i g. 3. Seasonal variation of the difference between the E100 and E30 kinetic energy density data: $a$ - at the $2.5 \mathrm{~m}$ horizon; $b$ - in the layer 50-300 m; $c$ - in the layer 700-2000 m

\section{Temperature}

According to E30 results, at the beginning of the year, the temperature in the surface layer is lower than according to E100 data by about $1{ }^{\circ} \mathrm{C}$. From midJanuary to mid-March, the temperature spatial distribution in E30 and E100 differed insignificantly. Since mid-March, the temperature in E30 is higher than in E100: during this period in E30 the surface water heating is going on more rapidly. At the same time, the difference in temperature in the eastern part of the sea and on the northwestern shelf (NWS) reached $2{ }^{\circ} \mathrm{C}$. Such features were noted until the beginning of August. At the end of summer, the greatest differences were obtained in the western and southeastern parts of the sea. The minimum difference between the results of performed experiments was detected in August. Since September, the waters in E30 were already about $1{ }^{\circ} \mathrm{C}$ colder and cooled faster than in E100.

Significant differences in the modeled temperature fields were noted in 30-50 m layer. In January - February, the greatest difference (up to $2{ }^{\circ} \mathrm{C}$ ) was typical for the NWS. In April, in the Sevastopol anticyclone region the difference in temperature was about $1^{\circ} \mathrm{C}$ in this layer. In E30, spring warming was more rapid, especially in the northwestern part of the continental slope. By mid-July, the temperature spatial distribution in 30-50 m layer, became qualitatively similar in E100 and E30, but in E30 its values were still $0.5-1{ }^{\circ} \mathrm{C}$ higher. By midSeptember, the western part of the sea in E30 was heat up by about $1^{\circ} \mathrm{C}$ more compared to E100.

Since the end of November in E30, temperature have been decreasing at a faster rate, especially in the NWS area. On average, at $30 \mathrm{~m}$ horizon in E30, the temperature was about $1{ }^{\circ} \mathrm{C}$ lower, while at $50 \mathrm{~m}$ horizon, the data in E30 and E100 were qualitatively and quantitatively similar. At a depth of $100 \mathrm{~m}$ during the year, the temperature differences between E100 and E30 are insignificant. At $500 \mathrm{~m}$ horizon in E30, a wider area of waters with a temperature exceeding $8.883^{\circ} \mathrm{C}$ was distinguished. Deeper, there was no significant difference and noticeable detailing of the temperature field structure in E30 compared to E100.

In Fig. 4 the thinning and «break» of CIL (according to the $8{ }^{\circ} \mathrm{C}$ criterion) in the central part of the sea, as well as an increase in temperature in the upper mixed layer in E30 compared to E100, are shown. This indicates an increase in the heat content of the upper sea layer in the last 30 years. 


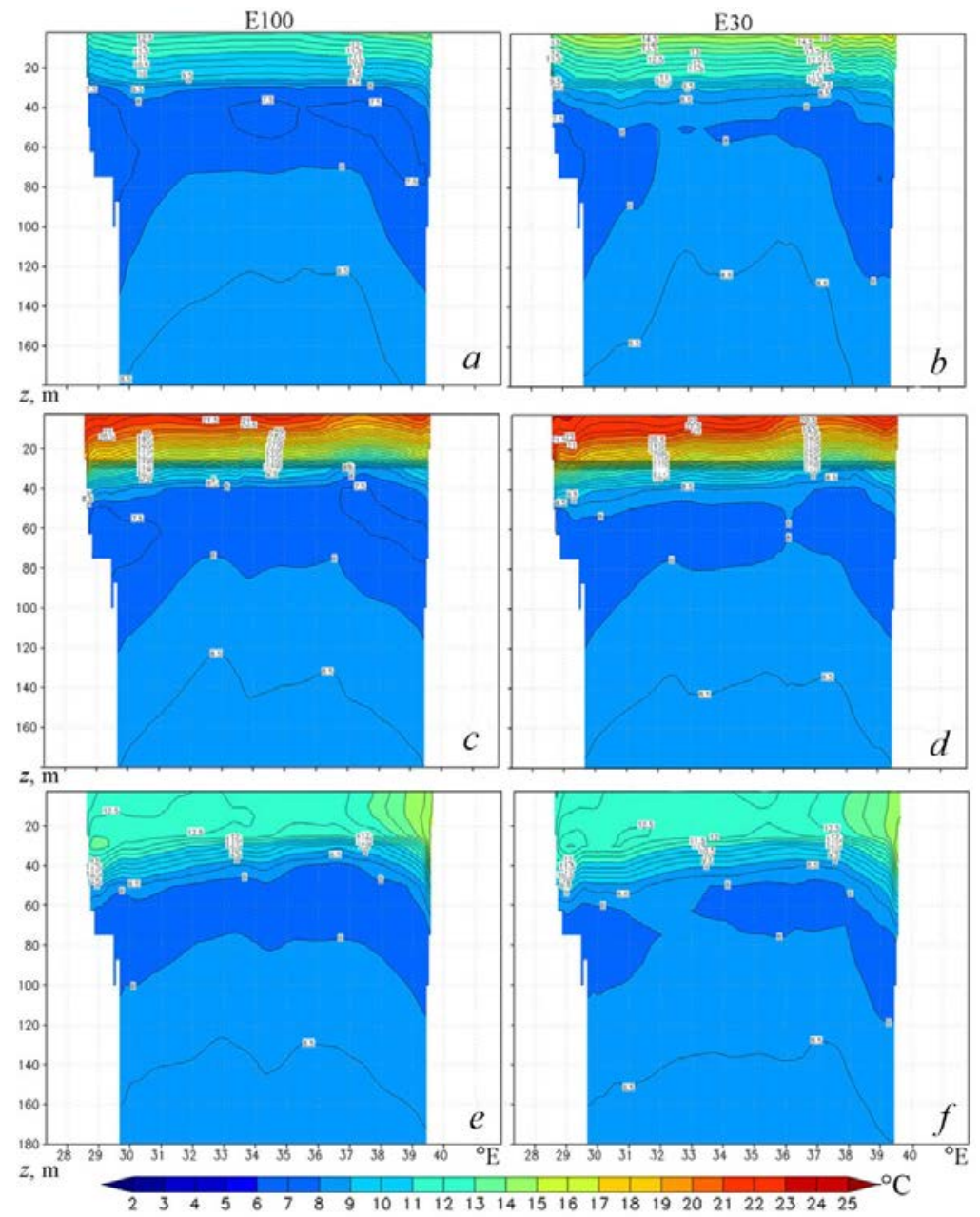

F i g. 4. Temperature in the layer $0-180 \mathrm{~m}$ on the section along $43.6^{\circ} \mathrm{N}$ according to the E100 (left) and E30 (right) data, calculated for May, $7(a, b)$, August, $2(c, d)$ and November, $18(e, f)$

\section{Salinity}

In 2.5-5 m layer, throughout the year the waters with salinity exceeding 18.3 \% occupied a larger area in the sea central part in E30 as compared to E100. From January to mid-March, the maximum salinity in E30 was $18.6 \%$, while in E100 it did not exceed $18.4 \%$. The minimum salinity difference between the results of the experiments was detected in the spring-summer season in the 30-50 m layer. In the eastern part of the sea, the differences were the maximum - up to $0.2 \%$ in winter. In E30, more saline waters were observed in the central part of the sea throughout the year than in E100. At the same time, at the NWS salinity was lower in E30, and the salinity difference between E100 and $\mathrm{E} 30$ was $\sim 0.15 \%$ at the region.

At $100-500$ m horizons, the salinity fields in E100 and E30 did not differ qualitatively. The main differences were detected near the continental slope, in areas with intense mesoscale variability. The greatest difference in the salinity field PHYSICAL OCEANOGRAPHY VOL. 28 ISS. 4 (2021) 
structure was revealed at the depths of more than $700 \mathrm{~m}$. In E30, the fields were significantly inhomogeneous - the data spatial distribution showed the existence of areas with increased and decreased salinity values, in contrast to the much smoother field in E100 (Fig. 5, $a, c$ ).
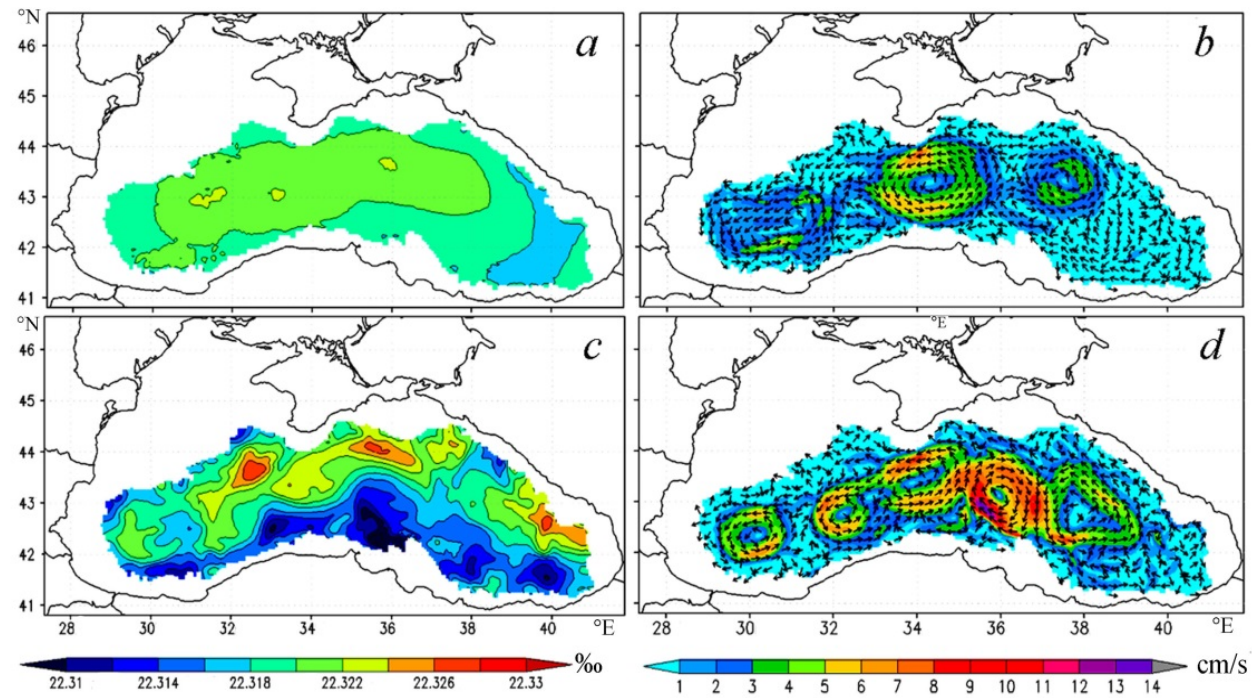

F i g. 5. Fields of salinity $(a, c)$ and currents $(b, d)$ at the $1500 \mathrm{~m}$ horizon calculated for March, 19 according to the $\mathrm{E} 100(a, b)$ and E30 $(c, d)$ data

\section{Currents}

Both experiments reproduced the well-known features of the Black Sea circulation - the Rim Current, the eastern and western cyclonic gyres, quasistationary eddies of Sevastopol and Batumi anticyclones. In Fig. 6 the fields of currents at $5 \mathrm{~m}$ horizon in summer are represented. It can be seen that the general structure of the obtained fields is similar. However, the maximum velocities in E30 were on average $2-3 \mathrm{~cm} / \mathrm{s}$ higher. It could be caused by an increase in the horizontal density gradients due to an improved spatial resolution in the assimilated array.

According to E30, the Rim Current meandering was detected throughout the year in 30-50 m layer in the central part of the Anatolian coast, and an intensification of Batumi anticyclone in comparison with E100 results was revealed. According to E100 data, at $100 \mathrm{~m}$ horizon from February to May, the Rim Current southwestern branch was more intense and narrow than in E30. At the same time, according to E30 data, the velocities in the Rim Current along the eastern part of the Anatolian coast and the Caucasian coast were higher. 


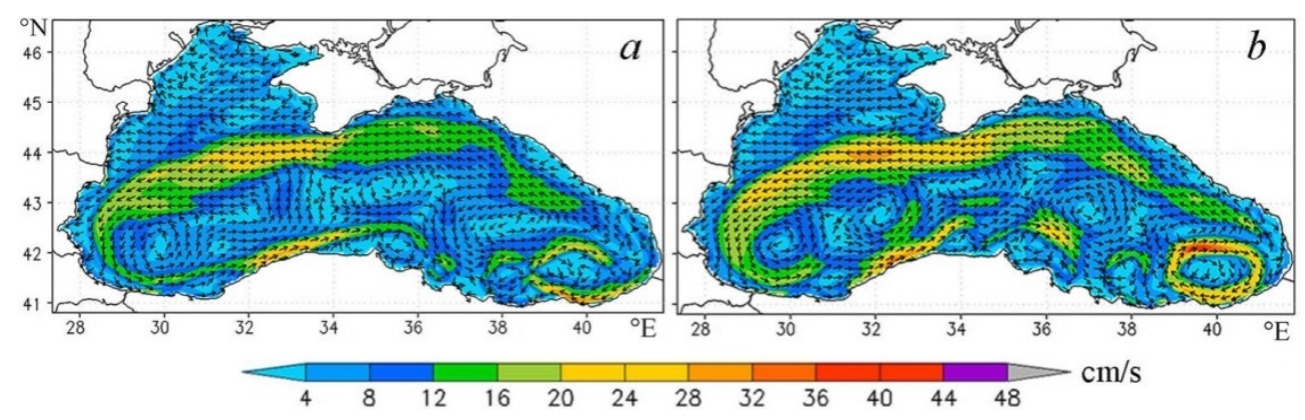

F i g. 6. Currents at the $5 \mathrm{~m}$ horizon calculated for July, 19 according to: $a-\mathrm{E} 100$ and $b-\mathrm{E} 30$ data

In the velocity fields obtained in both experiments, the presence of cyclonic and anticyclonic eddies is also detected at horizons of more than $500 \mathrm{~m}$. In the deep-water part of the sea, the number of eddies in E30 is greater than in E100 (Fig. 5, b, d). The eddies in the abyssal area retained their structure down to the bottom. The difference in the number and intensity of eddies in the considered experiment results is apparently due to significant inhomogeneities of the density field, calculated with the assimilation of HC30 data in the model.

The abovementioned differences in the thermohaline and hydrodynamic characteristics of the Black Sea, obtained using the data of HC100 and HC30 arrays, are due to two main reasons. For climatic averages in the upper sea layer, long-term variability is a very significant factor. The period 1991-2020 was characterized by a rather rapid change in the state of the Black Sea: from cold to warmer and from less to more saline. Accordingly, the distribution of data over the years affects the average characteristics of the entire period. For deep layers, where the spatial-temporal variability at all scales is very small, the quality of the measurements is extremely important. Problems with the stability and calibration of observing devices and sensors installed on platforms submerged in seawater for a long time are most noticeable for autonomous profiling floats of the early 2000s (first generation). The intercalibration of shipborne CTD-probes, widely used by various organizations, was carried out only during the Black Sea international surveys in the 1990s. This situation leads to an increase in the level of high-frequency noise, which is difficult to completely filter out when calculating the average fields.

\section{Conclusion}

The performed numerical experiments on the modeling of the Black Sea dynamics with the assimilation of two different climatic temperature and salinity arrays revealed the following. Significant difference was obtained in the modeled fields reconstructed with the assimilation of the temperature and salinity climatic array according to observational data for 1910-2003 and for the recent 30 years. It includes an increase in the integral temperature of the upper mixed layer, thinning and "break" of the CIL (according to $8{ }^{\circ} \mathrm{C}$ criterion) in the sea central part, which indicates a warming of the upper water layer over the past 30 years. The increased noise level in salinity fields revealed at deep-water horizons in the experiment with the new array assimilation is associated with the quantity and 
quality of recently obtained observational data. Taking into account the insufficient calibration support of measurements of the seawater electrical conductivity for the next climatic array version, a more stringent procedure for checking and filtering observational data in the Black Sea deep layers is required.

\section{REFERENCES}

1. Demyshev, S.G. and Korotaev, G.K., 1992. [Numerical Energy-Balanced Model of the Baroclinic Currents in Ocean with Uneven Bottom on a C-Grid]. In: INM RAS, 1992. [Numerical Models and Results of Calibration Calculations of Currents in the Atlantic Ocean: Atmosphere - Ocean - Space. The Program «Sections»]. Moscow: Institute of Numerical Mathematics RAS, pp. 163-231 (in Russian).

2. Demyshev, S.G., Knysh, V.V. and Korotaev, G.K., 2006. Calculation of Adapted Black Sea Fields on the Basis of Assimilation of Climatic Temperature and Salinity Data into the Model. Izvestiya, Atmospheric and Oceanic Physics, 42(5), pp. 555-567. doi:10.1134/S0001433806050033

3. Knysh, V.V., Demyshev, S.G. and Korotaev, G.K., 2002. A Procedure of Reconstruction of the Climatic Seasonal Circulation in the Black Sea Based on the Assimilation of Hydrological Data in the Model. Physical Oceanography, 12(2), pp. 88-103. doi:10.1023/A:1014869107470

4. Knysh, V.V., Korotaev, G.K., Demyshev, S.G. and Belokopytov, V.N., 2005. Long-Term Variations of the Thermohaline and Dynamic Characteristics of the Black Sea According to the Climatic Data on Temperature and Salinity and Their Assimilation in the Model. Physical Oceanography, 15(3), pp. 142-160. doi:10.1007/s11110-005-0037-y

5. Demyshev, S.G., Knysh, V.V. and Inyushina, N.V., 2005. Seasonal Variations and Transformations of Climatic Currents with Depth on the Basis of Assimilation of New Climatic Data on Temperature and Salinity in a Model of the Black Sea. Physical Oceanography, 15(6), pp. 346-362. doi:10.1007/s11110-006-0008-y

6. Dorofeev, V.L. and Korotaev, G.K., 2004. Assimilation of the Data of Satellite Altimetry in an Eddy-Resolving Model of Circulation of the Black Sea. Physical Oceanography, 14(1), pp. 42-56. doi:10.1023/B:POCE.0000025369.39845.c3

7. Demyshev, S.G., Ivanov, V.A., Markova, N.V. and Cherkesov, L.V., 2007. Construction of the Black Sea Currents on the Basis of Eddy Resolving Model with Assimilation of the Climatic Temperature and Salinity. In: MHI, 2007. Ekologicheskaya Bezopasnost' Pribrezhnykh i Shel'fovykh Zon i Kompleksnoe Ispol'zovanie Resursov Shel'fa [Ecological Safety of Coastal and Shelf Zones and Comprehensive Use of Shelf Resources]. Sevastopol: ECOSI-Gidrofizika. Iss. 15, pp. 215-226 (in Russian).

8. Demyshev, S.G. and Knysh, V.V., 2004. Reconstruction of the Adapted Vertical Velocity of the Black Sea Based on the Synthesis of the Circulation Model and Climatic Data on Temperature and Salinity. In: MHI, 2004. Ekologicheskaya Bezopasnost' Pribrezhnykh i Shel'fovykh Zon i Kompleksnoe Ispol'zovanie Resursov Shel'fa [Ecological Safety of Coastal and Shelf Zones and Comprehensive Use of Shelf Resources]. Sevastopol: ECOSIGidrofizika. Iss. 11, pp. 93-104 (in Russian).

9. Mamayev, O.I., 1975. Temperature - Salinity Analysis of World Ocean Waters. Amsterdam: Elzevier, $374 \mathrm{p}$.

10. Staneva, J.V. and Stanev, E.V., 1998. Oceanic Response to Atmospheric Forcing Derived from Different Climatic Data Sets. Intercomparison Study for the Black Sea. Oceanologica Acta, 21(3), pp. 393-417. doi:10.1016/S0399-1784(98)80026-1

11. Efimov, V.V. and Timofeev, N.A., 1990. Heat-Balance Exploration of the Black and Azov Seas. Obninsk: VNIIGMI-MTsD, 236 p. (in Russian).

12. Pacanowski, R.C. and Philander, S.G.H., 1981. Parameterization of Vertical Mixing in Numerical Models of Tropical Oceans. Journal of Physical Oceanography, 11(11), pp. 14431451. https://doi.org/10.1175/1520-0485(1981)011<1443:POVMIN>2.0.CO;2 
13. Arakawa, A. and Lamb, V.R., 1981. A Potential Enstrophy and Energy Conserving Scheme for the Shallow Water Equation. Monthly Weather Review, 109(1), pp. 18-36. https://doi.org/10.1175/1520-0493(1981)109\%3C0018:APEAEC\%3E2.0.CO;2

14. Demyshev, S., Knysh, V., Korotaev, G., Kubryakov, A. and Mizyuk, A., 2010. The MyOcean Black Sea from a scientific point of view. Mercator Ocean Journal, Newsletter 39: MyOcean Physical Systems in Regional Seas, pp. 16-24. Available at: http://marine.copernicus.eu/wpcontent/uploads/2016/06/r63_9_quarterly_letter-_issue_39.pdf [Accessed: 08 July 2021].

15. Korotaev, G.K., Ratner, Yu.B., Ivanchik, M.V., Kholod, A.L. and Ivanchik, A.M., 2016. Operational System for Diagnosis and Forecast of Hydrophysical Characteristics of the Black Sea. Izvestiya, Atmospheric and Oceanic Physics, 52(5), pp. 542-549. https://doi.org/10.1134/S0001433816050078

16. Belokopytov, V.N., 2018. Retrospective Analysis of the Black Sea Thermohaline Fields on the Basis of Empirical Orthogonal Functions. Physical Oceanography, 25(5), pp. 380-389. doi:10.22449/1573-160X-2018-5-380-389

About the authors:

Natalia V. Markova, Junior Research Associate, Marine Hydrophysical Institute of RAS (2 Kapitanskaya St., Sevastopol, 299011, Russian Federation), SPIN-code: 3625-6866, ORCID ID: 0000-0002-7123-6657, ResearcherID: Q-2638-2017, Scopus Author ID: 57198013260, n.v.markova@mail.ru

Vladimir N. Belokopytov, Head of Oceanography Department, Marine Hydrophysical Institute of RAS (2 Kapitanskaya St., Sevastopol, 299011, Russian Federation), Dr. Sci. (Geogr.), SPIN-code: 5697-5700, ORCID ID: 0000-0003-4699-9588, ResearcherID: ABA-1230-2020, Scopus Author ID: 6602381894, v.belokopytov@gmail.com

Olga A. Dymova, Senior Research Associate, Marine Hydrophysical Institute of RAS (2 Kapitanskaya St., Sevastopol, 299011, Russian Federation), Ph. D. (Phys.-Math.), SPIN-code: 7565-1082, ORCID ID: 0000-0003-4036-2447, ResearcherID: P-9669-2015, Scopus Author ID: 6508381809, olgadym@yahoo.com

Nadezhda A. Miklashevskaya, Junior Research Associate, Marine Hydrophysical Institute of RAS (2 Kapitanskaya St., Sevastopol, 299011, Russian Federation), SPIN-code: 8476-2604, ORCID ID: 0000-0003-2619-343X, ResearcherID: P-2167-2017, Scopus Author ID: 8523715300, nmikl@rambler.ru

Contribution of the co-authors:

Natalia V. Markova - general scientific supervision of research; analysis, interpretation and discussion of the results; formulation of conclusions; preparing and editing the paper

Vladimir N. Belokopytov - development of methods and calculations of temperature and salinity climatic fields; qualitative and quantitative analysis of research results and preparation of initial conclusions; discussion of the research results; editing and supplementing the text of the paper

Olga A. Dymova - improvement of the MHI model; preparation and carrying out of numerical experiments; visualization of numerical experiments results; analysis of the results and their interpretation

Nadezhda A. Miklashevskaya - processing and description of research results; qualitative and quantitative analysis of the results; visualization of the research results; critical analysis and revision of the text

All the authors have read and approved the final manuscript.

The authors declare that they have no conflict of interest. 